Check for updates

Cite this: Chem. Sci., 2019, 10, 5898

๑ All publication charges for this article have been paid for by the Royal Society of Chemistry

Received 7th February 2019

Accepted 25th April 2019

DOI: $10.1039 / \mathrm{c} 9 \mathrm{sc} 00658 \mathrm{c}$

rsc.li/chemical-science

\section{Synergetic interaction between neighboring platinum and ruthenium monomers boosts $\mathrm{CO}$ oxidation $\uparrow$}

\author{
Peng Zhou, ${ }^{a}$ Xingang Hou, ${ }^{b}$ Yuguang Chao, ${ }^{a}$ Wenxiu Yang, ${ }^{a}$ Weiyu Zhang, ${ }^{a}$ Zijie Mu, ${ }^{a}$ \\ Jianping Lai, ${ }^{a c}$ Fan Lv, (DD ${ }^{a}$ Kuan Yang, ${ }^{d}$ Yuxi Liu, ${ }^{d}$ Jiong Li, (iD) Jingyuan Ma, ${ }^{e}$ Jun Luo ${ }^{b}$ \\ and Shaojun Guo (D) *afg
}

\begin{abstract}
Sub-nanometer noble metal catalysts, especially single atom (SA), are a new class of catalytic materials for boosting catalysis and possess unique catalytic properties and high atomic utilization efficiency. Exploring the interaction between two neighboring atom monomers has great potential to further improve the performance of SA catalysts and deepen the understanding on the catalytic mechanism of heterogeneous catalysis at the atomic level. Herein, we demonstrate that the synergetic effect between neighboring $\mathrm{Pt}$ and $\mathrm{Ru}$ monomers supported on $\mathrm{N}$ vacancy-rich $\mathrm{g}-\mathrm{C}_{3} \mathrm{~N}_{4}$ promotes the catalytic $\mathrm{CO}$ oxidation. The experimental observation and theoretical simulation reveal that the $\mathrm{N}$ vacancy in the g- $\mathrm{C}_{3} \mathrm{~N}_{4}$ structure builds an optimized triangular sub-nanometer cavity for stabilizing the neighboring Pt$\mathrm{Ru}$ monomers by forming $\mathrm{Pt}-\mathrm{C}$ and $\mathrm{Ru}-\mathrm{N}$ bonds. The mechanistic studies based on the in situ IR spectrum and theoretical simulation confirm that the neighboring Pt-Ru monomers possess a higher performance for optimizing $\mathrm{O}_{2}$ activation than $\mathrm{Ru}-\mathrm{Ru} / \mathrm{Pt}-\mathrm{Pt}$ monomers or isolated Ru/Pt atoms by balancing the energy evolution of reaction steps in the catalytic $\mathrm{CO}$ oxidation. The discovery of the synergetic effect between neighboring monomers may create a new path for manipulating the catalytic properties of SA catalysts.
\end{abstract}

Recently, sub-nanometer single atom (SA) metal catalysts have attracted increasing attention due to their significantly high atom utilization efficiency, low-coordination environment and strong metal-support effect. ${ }^{1-6}$ SA catalysts exhibit remarkable activity in a variety of catalytic reactions, including thermocatalytic oxidation, photocatalytic reduction and electrocatalytic

\footnotetext{
${ }^{a}$ Department of Materials Science and Engineering, Peking University, Beijing 100871, China.E-mail: guosj@pku.edu.cn

${ }^{b}$ Center for Electron Microscopy, Tianjin Key Laboratory of Advanced Functional Porous Materials, Institute for New Energy Materials \& Low-Carbon Technologies, School of Materials, Tianjin University of Technology, Tianjin 300384, China

${ }^{c}$ Key Laboratory of Eco-Chemical Engineering, Taishan Scholar Advantage and Characteristic Discipline Team of Eco Chemical Process and Technology, College of Chemistry and Molecular Engineering, Qingdao University of Science and Technology, Qingdao 266042, China

${ }^{d}$ Laboratory of Catalysis Chemistry and Nanoscience, Department of Chemistry and Chemical Engineering, College of Environmental and Energy Engineering, Beijing University of Technology, Beijing 100124, China

'Shanghai Synchrotron Radiation Facility, Shanghai Institute of Applied Physics, Chinese Academy of Sciences, Shanghai 201204, China

${ }^{f}$ The Beijing Innovation Center for Engineering Science and Advanced Technology, Peking University, Beijing 100871, China

${ }^{g}$ Key Laboratory of Theory and Technology of Advanced Batteries Materials, College of Engineering, Peking University, Beijing 100871, China

$\dagger$ Electronic supplementary information (ESI) available. See DOI: $10.1039 / \mathrm{c} 9 \mathrm{sc} 00658 \mathrm{c}$
}

hydrogenation..$^{7-12}$ More importantly, SA catalysts often follow different catalytic pathways from those of their nanocrystals, leading to product selectivity in catalytic reactions., ${ }^{\mathbf{9 1 3}-17}$ Furthermore, decreasing the distance between two active SA centers to the sub-nanometer scale has been revealed to have a significant effect on their catalytic behavior. ${ }^{11}$ For instance, isolated $\mathrm{Pt}$ monomers favored the conversion of $\mathrm{CO}_{2}$ into methanol without the formation of formic acid, whereas $\mathrm{CO}_{2}$ was reduced to formic acid on two neighboring Pt monomers. ${ }^{18}$ Moreover, $\mathrm{Fe}_{2}$ clusters on $\mathrm{g}-\mathrm{C}_{3} \mathrm{~N}_{4}$ were confirmed to possess a higher performance for producing active oxygen species than isolated $\mathrm{Fe}$ atoms, leading to their unique reactivity for the epoxidation of trans-stilbene to trans-stilbene oxide. ${ }^{19}$ In those cases, the chemical environments and species of two neighboring monomers are both the same, which limits the diversity of catalytic behavior. Designing two different neighboring monomers probably provides a strategy to reach this target. Furthermore, the lattice limitation from the support often inhibits the formation of two neighboring monomers. Optimizing the surface defect of the support to stabilize the coordination structure of two neighboring monomers is significant for preparing a high-performance catalyst. ${ }^{4,14,20,21}$

Herein, we report neighboring $\mathrm{Pt}$ and $\mathrm{Ru}(\mathrm{Pt}-\mathrm{Ru})$ monomers on $\mathrm{N}$-vacancy-rich $\mathrm{g}-\mathrm{C}_{3} \mathrm{~N}_{4}$ for the catalytic $\mathrm{CO}$ oxidation by an 
icing-assisted photocatalytic reduction method. X-ray absorption fine structure (XAFS) and high-angle annular dark fieldscanning transmission electron microscopy (HAADF-STEM) results confirm that the surface of $\mathrm{g}-\mathrm{C}_{3} \mathrm{~N}_{4}(\mathrm{CN})$ is covered with the high-density Pt-Ru monomers. The theoretical simulations suggest that the $\mathrm{N}$ vacancy in the $\mathrm{g}-\mathrm{C}_{3} \mathrm{~N}_{4}$ structure builds an optimized triangular sub-nanometer cavity for stabilizing the neighboring $\mathrm{Pt}-\mathrm{Ru}$ monomers by forming $\mathrm{Pt}-\mathrm{C}$ and $\mathrm{Ru}-\mathrm{N}$ bonds. X-ray absorption near-edge structure (XANES) and X-ray photoelectron spectroscopy (XPS) indicate that the $\mathrm{Ru}$ monomer and $\mathrm{N}$ vacancy synergistically increase the electron density of the neighboring Pt monomer. The catalytic CO oxidation shows that the formation of electron-rich Pt-Ru monomers in the $\mathrm{N}$ vacancy region contributes to improved catalytic activity. The mechanism study based on the in situ IR spectrum and theoretical simulation suggests that the catalytic CO oxidation on Pt-Ru monomers supported by $\mathrm{CN}$ follows the Eley-Rideal (E-R) mechanism, in which the electron-rich Pt-Ru monomers optimize the $\mathrm{O}_{2}$ activation by causing bridge-type $\mathrm{O}_{2}$ adsorption between $\mathrm{Pt}$ and $\mathrm{Ru}$ compared to the $\mathrm{Ru}-\mathrm{Ru} / \mathrm{Pt}-\mathrm{Pt}$ monomers or the isolated $\mathrm{Ru} / \mathrm{Pt}$ atoms. The discovery of the synergetic interaction between two neighboring different monomers may create a path for manipulating the catalytic properties of SA catalysts.

In a typical synthesis of $\mathrm{C}_{3} \mathrm{~N}_{4}$ nanosheets, pure g- $\mathrm{C}_{3} \mathrm{~N}_{4}$ was synthesized by annealing dicyandiamide at $500{ }^{\circ} \mathrm{C}$ in air, and denoted as $\mathrm{CN}^{22,23}$ Then, $\mathrm{N}$ vacancies were introduced into g$\mathrm{C}_{3} \mathrm{~N}_{4}$ by treatment at $620{ }^{\circ} \mathrm{C}$ in $\mathrm{N}_{2}$, and denoted as CN620. X-ray diffraction (XRD) patterns of $\mathrm{CN}$ and $\mathrm{CN} 620$ show a diffraction peak at $27.2^{\circ}$ (Fig. S1a $\dagger$ ), indexed to typical g- $\mathrm{C}_{3} \mathrm{~N}_{4} \cdot{ }^{22,24}$ Besides, the intensity of the diffraction peak at $27.2^{\circ}$ in $\mathrm{CN} 620$ is weaker than that in $\mathrm{CN}$, implying the weakening of crystallinity and formation of defects. The UV-vis diffuse reflectance spectra (DRS) reveal that a progressive redshift in the absorption edge is achieved from CN to CN620 (Fig. S1b†). The bandgaps of the different $\mathrm{CN}$ determined from the transformed Kubelka-Munk function progressively narrow from $2.62 \mathrm{eV}$ for $\mathrm{CN}$ to $2.14 \mathrm{eV}$ for CN620 (the inset of Fig. S1b $\dagger$ ). This redshift results from the formation of $\mathrm{N}$ vacancies. ${ }^{25,26}$ In the structure of $\mathrm{g}-\mathrm{C}_{3} \mathrm{~N}_{4}$, the $\mathrm{C}$ atoms are coordinated to three $\mathrm{N}$ atoms, while some $\mathrm{N}$ atoms are only coordinated to two $\mathrm{C}$ atoms (Fig. 1a). According to the structure simulation, the largest vertical dimension in pristine $\mathrm{CN}$ is $4.20 \AA$. However, with the formation of $\mathrm{N}$ vacancies, two neighboring two-coordinated $\mathrm{C}$ atoms $\left(\mathrm{C}_{2 \mathrm{C}}\right)$ were left. The largest vertical dimension in $\mathrm{N}$-vacancy-modified $\mathrm{CN}$ is remarkably increased to $5.47 \AA$. This greatly improves the possibility of creating two neighboring monomers, like Pt and $\mathrm{Ru}$ atoms with a diameter of approximate $2.2 \AA$. According to a recent report, the $\mathrm{N}$ vacancy in $\mathrm{CN}$ is a photogeneratedelectron-rich region, which can reduce the precursor ions of noble metals to monomer atoms. ${ }^{26}$

Based on the above speculation, Pt-Ru monomer-loaded CN620 (PtRuSA-CN620) was prepared by the method illustrated in Fig. 1a. The CN620 photocatalyst and Pt/Ru precursor $\left(\mathrm{H}_{2} \mathrm{PtCl}_{6}\right.$ and $\left.\mathrm{RuCl}_{3}\right)$ were mixed in deionized water, and then rapidly frozen in liquid nitrogen to form an ice bulk..$^{27,28}$ On the CN620 surface, the $\mathrm{C}_{2 \mathrm{C}}$ and $\mathrm{N}_{2 \mathrm{C}}$ sites were positively and negatively charged due to their different electronegativity, respectively. Hence, the negatively charged $\left[\mathrm{PtCl}_{6}\right]^{2-}$ ion and positively charged $\mathrm{Ru}^{3+}$ tended to be selectively adsorbed at the $\mathrm{C}_{2 \mathrm{C}}$ and $\mathrm{N}_{2 \mathrm{C}}$ sites, respectively. A $300 \mathrm{~W}$ Xe lamp was used as the light source to excite $\mathrm{g}-\mathrm{C}_{3} \mathrm{~N}_{4}$ in the ice bulk to produce
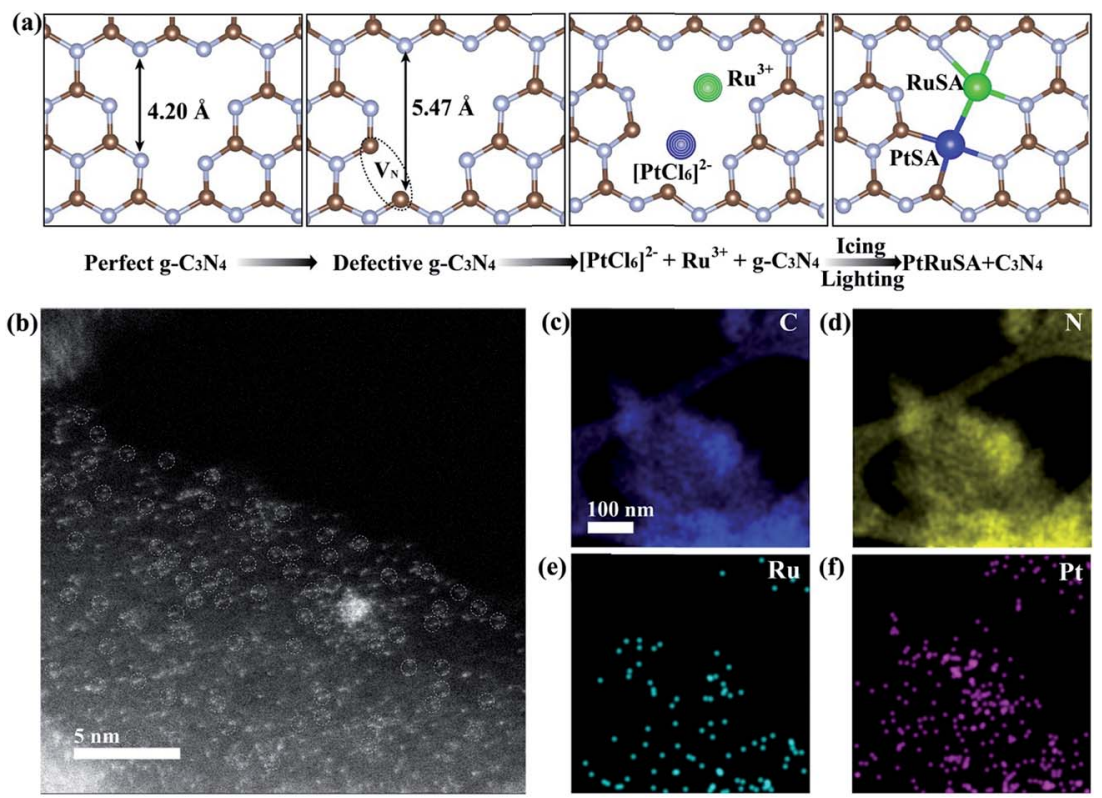

Fig. 1 (a) Schematic illustration of the icing-assisted in situ photocatalytic reduction method for preparing PtRuSA-CN620. (b) HAADF-STEM images of PtRuSA-CN620 and the corresponding distribution of (c) C, (d) N, (e) Ru and (f) Pt. Scale bar: $5 \mathrm{~nm}$. 
photogenerated electrons. The photogenerated electrons reduced the adsorbed $\left[\mathrm{PtCl}_{6}\right]^{2-}$ and $\mathrm{Ru}^{3+}$ ions to $\mathrm{Pt}$ and $\mathrm{Ru}$ monomers, respectively. RuSA-CN620, PtSA-CN620 and PtRuSA-CN were obtained by a similar method by changing the species of the support and metal ions. For comparison, PtRu nanoparticle-loaded CN620 (PtRuNP-CN620) was prepared by directly irradiated the mixed solution of CN620 and the Pt/Ru precursor without the icing treatment. According to the ICPOES measurements, the Ru contents in RuSA-CN620, PtRuSACN620, PtRuSA-CN and PtRuNP-CN620 are 0.40, 0.45, 0.32 and 0.33 wt $\%$, respectively (Table $\mathrm{S} 1 \dagger$ ). The Pt contents in PtSACN620, PtRuSA-CN620, PtRuSA-CN and PtRuNP-CN620 are $1.34,0.51,0.59$ and $0.54 \mathrm{wt} \%$, respectively. These results suggest that the Ru and Pt contents in PtRuSA-CN620, PtRuSA-CN and PtRuNP-CN620 are similar.

Aberration-corrected HAADF-STEM was used to characterize the distribution of PtSA and RuSA on the as-prepared samples. In PtRuSA-CN620, the supra-high-density PtSA and RuSA are observed on the whole CN620 surface (Fig. 1b). Especially, a spacing of approximate $2.8 \AA$ are observed between two neighboring atom monomers, which is consistent with the theoretical structure (Fig. 1a). The corresponding elemental mapping confirms that $\mathrm{Pt}$ and $\mathrm{Ru}$ share a similar distribution, implying the existence of Pt-Ru monomers (Fig. 1c-f). It should be noted that it is still difficult to distinguish between PtSA and RuSA due to the vibration induced by the irradiation of the electron beam. Similarly, the HAADF-STEM images of RuSACN620 and PtSA-CN620 also show high-density RuSA and PtSA, respectively (Fig. S2†). Meanwhile, some $\mathrm{Ru}-\mathrm{Ru}$ or $\mathrm{Pt}-\mathrm{Pt}$ monomers are observed. However, the difference is that some remarkable RuNPs with a diameter of larger than $2 \mathrm{~nm}$ exist in RuSA-CN620 (Fig. S2a and $\mathrm{b}_{\dagger} \dagger$ ). In contrast, no observable PtNPs appear in PtSA-CN620 (Fig. S2c and $\mathrm{d} \dagger$ ). Interestingly, the aggregation of RuSAs in PtRuSA-CN620 is effectively inhibited in the presence of PtSAs (Fig. 1b). This implies the interaction between Pt and Ru. This is also observed in PtRuSA-CN though the aggregation degree of $\mathrm{Ru}$ is higher than that in PtRuSACN620 (Fig. S3†). As a comparison, numerous PtRuNPs are observed in PtRuNP-CN620 (Fig. S4 $\dagger$ ).

X-ray absorption fine structure (XAFS) measurements were carried out to investigate the coordination structures of $\mathrm{Ru}$ and Pt species at the atomic level. Fig. 2a and b show the Ru K-edge and $\mathrm{Pt} \mathrm{L}_{3}$-edge X-ray absorption near-edge structure (XANES) spectra of the as-prepared samples, respectively. The Ru K-edge absorption thresholds in RuSA-CN, PtRuSA-CN and PtRuSACN620 are nearly similar, which are lower than that of $\mathrm{Ru}$ foil. Hence, the chemical valences of $\mathrm{Ru}$ in the prepared samples are more positive than that of $\mathrm{Ru}^{0}$ in $\mathrm{Ru}$ foil, but less positive than that of $\mathrm{Ru}^{3+}$ in $\mathrm{RuCl}_{3}$ according to the previous literature. ${ }^{10}$ The $\mathrm{Pt} \mathrm{L}_{3}$-edge of PtRuSA-CN and PtRuSA-CN620 is higher than that of PtSA-CN620, but lower than that of Pt foil. This suggests that the existence of RuSA increases the electron density of PtSA in PtRuSA-CN and PtRuSA-CN620. Moreover, the Pt $\mathrm{L}_{3}$-edge of PtRuSA-CN620 is higher than that of PtRuSA-CN. Thus the chemical valences of Pt in PtSA-CN620 and PtRuSA-CN is less negative than that in PtRuSA-CN620, but more negative than that of $\mathrm{Pt}^{4+}$ in $\mathrm{H}_{2} \mathrm{PtCl}_{6}$ according to the previous literature. ${ }^{29}$ The
Fourier-transformed (FT) $k^{3}$-weighted extended X-ray absorption fine structure (EXAFS) spectra of Ru further reveal that one main peak at $1.57 \AA$ is observed in RuSA-CN, PtRuSA-CN and PtRuSA-CN620 (Fig. 2c), corresponding to the first coordination shell of Ru. ${ }^{10}$ Similarly, one main peak at $1.60 \AA$ in the FT $k^{3}$ weighted EXAFS spectra of Pt corresponds to the first coordination shell of Pt in PtSA-CN, PtRuSA-CN and PtRuSA-CN620 (Fig. 2d). ${ }^{26,29}$ Relatively weak peaks ranging from $2 \AA$ to $3 \AA$ are also observed in PtRuSA-CN and PtRuSA-CN620, which are probably attributed to the $\mathrm{Ru}-\mathrm{Ru}$ or $\mathrm{Ru}-\mathrm{Pt}$ coordination shell of Ru (Fig. S5 $\dagger$ ). To obtain the quantitative chemical configurations of RuSA and PtSA, EXAFS fitting was performed to extract the structural parameters (Fig. S6 and S7 $\dagger$ ). The centered $\mathrm{Ru}$ atoms possess three coordinating interactions: $\mathrm{Ru}-\mathrm{N}, \mathrm{Ru}-\mathrm{C}$ and $\mathrm{Ru}-\mathrm{Ru} / \mathrm{Pt}$ (Table $\mathrm{S} 2 \dagger$ ). It should be noted that it is commonly difficult to distinguish between $\mathrm{Ru} / \mathrm{Pt}-\mathrm{N}$ and $\mathrm{Ru} / \mathrm{Pt}-\mathrm{O}$ coordination due to their similar bond length. Thus the fitted $\mathrm{Ru}-\mathrm{N}$ coordination probably contains $\mathrm{Ru}-\mathrm{O}$ coordination. The coordination number of Ru-N in RuSA-CN620, PtRuSA-CN620 and PtRuSA-CN is 7.81, 2.20 and 6.50, respectively. However, the coordination number of Ru-C in RuSA-CN620, PtRuSA-CN620 and PtRuSA-CN is $0.43,3.48$ and 2.58, respectively. This suggests that the introduction of $\mathrm{Pt}$ greatly promotes the formation of $\mathrm{Ru}-\mathrm{C}$ coordination bonds between CN620 and Ru. This is considered to be due to the reason that the Pt-promoted atomic dispersion of $\mathrm{Ru}$ leads to the production of more chemical bonds between CN620 and Ru, especially Ru-C. Besides, numerous $\mathrm{N}$ vacancies in CN620 also contribute to high coordination numbers of $\mathrm{Ru}-\mathrm{C}$ in PtRuSA-CN620 due to the more unsaturated $\mathrm{C}_{2 \mathrm{C}}$ atoms. The fitting results of $\mathrm{Ru}$ show that the coordination numbers of $\mathrm{Ru}-\mathrm{Ru}$ (0.36) in PtRuSACN620 is smaller than that (1.38) in RuSA-CN620, and meantime, $\mathrm{Ru}-\mathrm{Pt}$ with a coordination number of 0.72 is obtained, indicating the direct interaction between $\mathrm{Pt}$ and $\mathrm{Ru}$. This strongly confirms the existence of numerous neighboring Pt-Ru monomers, which well explains the Pt-promoted atomic dispersion of $\mathrm{Ru}$ in the above STEM characterization. However, it should be noted that the higher content of $\mathrm{Ru}-\mathrm{Pt}$ coordination in PtRuSA-CN is probably originated from the formation of more RuPt alloy clusters or particles according to the above STEM observations (Fig. S3†). This also implies the important role of $\mathrm{N}$ vacancies in the formation of neighboring $\mathrm{Pt}-\mathrm{Ru}$ monomers. Similarly, the existence of $\mathrm{Ru}$ also influences the coordination structure of $\mathrm{Pt}$ (Table $\mathrm{S} 3 \dagger$ ). The coordination number of Pt-C in PtSA-CN620 is decreased from 2.02 to 1.29 in PtRuSA-CN620. Meanwhile the coordination number of $\mathrm{Pt}-\mathrm{N}$ is also decreased from 5.62 to 3.43 , which is attributed to the formation of Pt-Ru bonds with a coordination number of 0.98 . Besides, the Pt-C coordination in PtRuSA-CN is negligible due to the fewer $\mathrm{N}$ vacancies in $\mathrm{CN}$. Similarly, the high coordination number (1.34) of Pt-Ru can also be attributed to the formation of some RuPt alloy clusters or particles, which is approximate to the fitting results of Ru. The wavelet transform (WT) is used to analyze $\mathrm{Ru}$ K-edge (Fig. 2e) and $\mathrm{Pt} \mathrm{L}_{3}$-edge (Fig. 2f) EXAFS oscillations. The WT maximum of Ru at 4.6 and Pt at $5.6 \AA^{-1}$ could be assigned to the $\mathrm{Ru}-\mathrm{C} / \mathrm{N} / \mathrm{O}$ bonding and $\mathrm{Pt}-\mathrm{C} / \mathrm{N} / \mathrm{O}$, respectively. The above XAFS confirms the existence of 

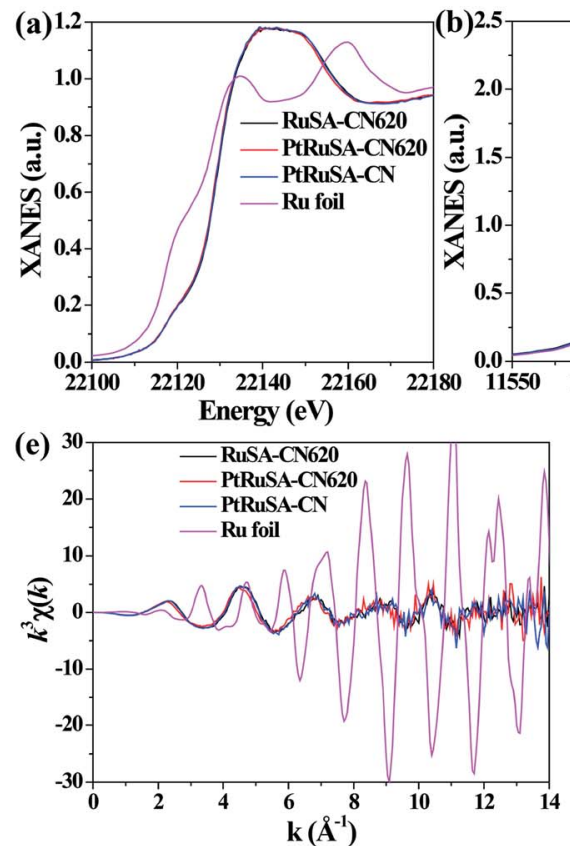

(h)

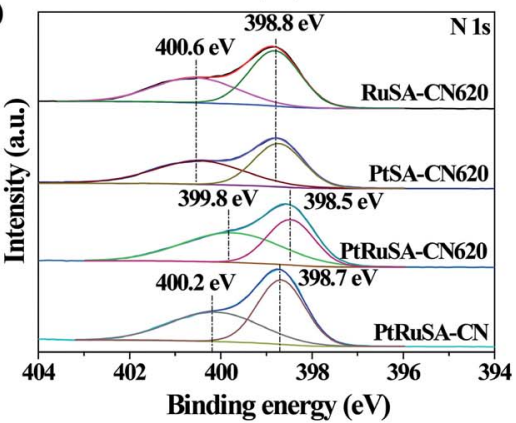

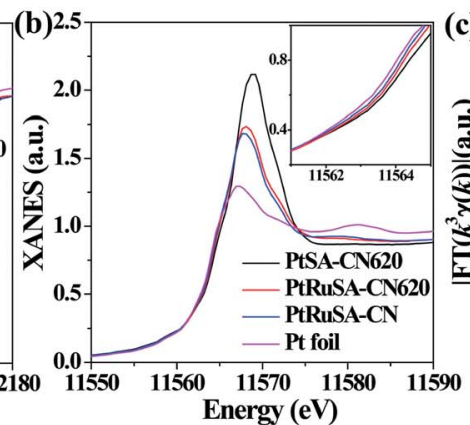

(f) ${ }^{20}$

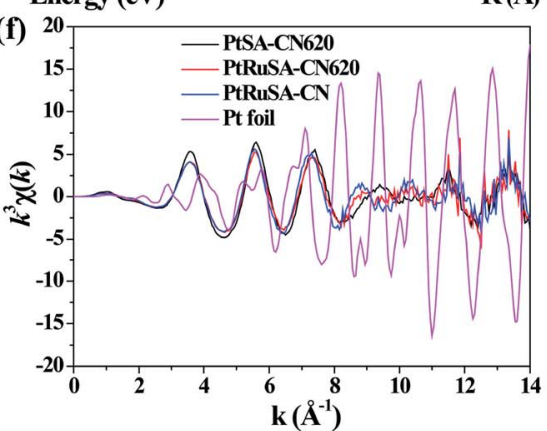

(i)

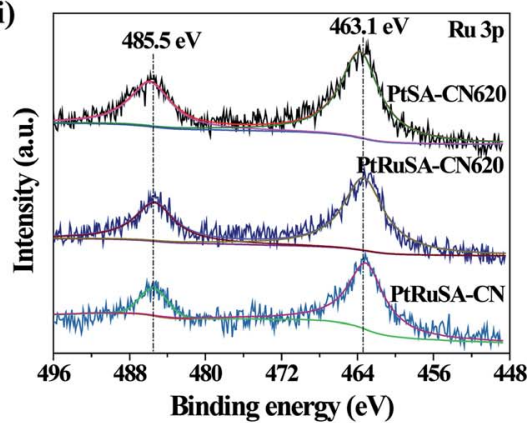

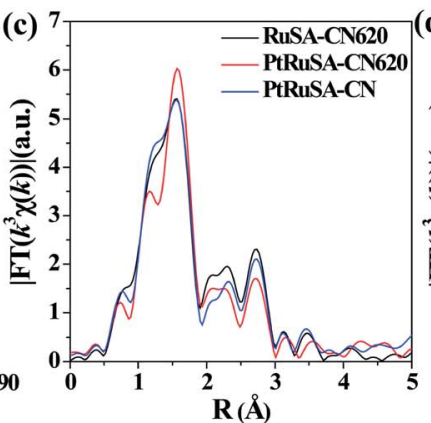

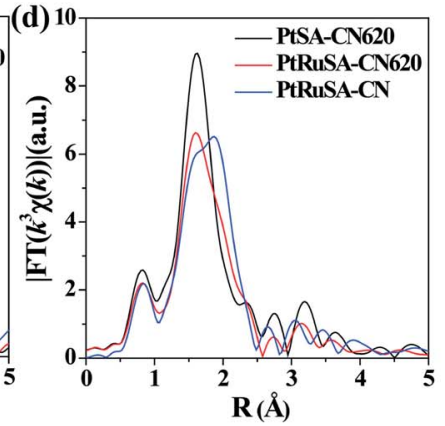

(g)

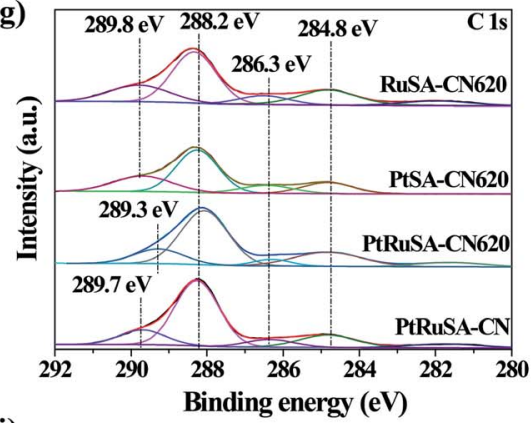

(j)

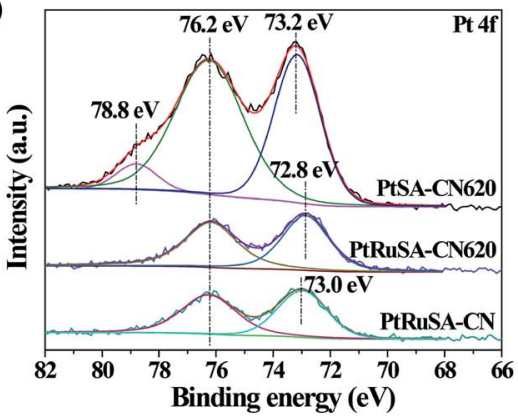

Fig. 2 (a) Ru K-edge and (b) Pt $L_{3}$-edge XANES spectra of as-prepared samples and the corresponding $k^{3}$-weighted FT spectra of Ru and Pt at (c and d) $R$ space and (e and f) $k$ space. XPS survey spectra of (g) C 1s, (h) N 1s, (i) Ru 3p and (j) Pt $4 f$ of as-prepared samples.

neighboring Pt-Ru monomers in PtRuSA-CN620 and the important role of $\mathrm{N}$ vacancies in the formation of neighboring $\mathrm{Pt}-\mathrm{Ru}$ monomers.

To explore the relationship between the coordination structure and electronic properties of Pt-Ru monomers, X-ray photoelectron spectroscopy (XPS) was used to analyze the chemical state of Pt-Ru monomers and $\mathrm{C}_{3} \mathrm{~N}_{4}$. In the $\mathrm{C} 1 \mathrm{~s}$ spectrum, a dominant $\mathrm{C} 1 \mathrm{~s}$ peak at $288.2 \mathrm{eV}$ corresponds to the three-coordinated $\mathrm{C}_{3 \mathrm{C}}$ groups (Fig. 2g). ${ }^{22}$ The weak peak at binding energy larger than $288.2 \mathrm{eV}$ is attributed to the $\mathrm{C}$ species binding with metal or $\mathrm{O}$ atoms. Especially, the peak at $289.3 \mathrm{eV}$ in PtRuSA-CN620 is lower than those in RuSA-CN620 (289.8 eV), PtSA-CN620 (289.8 eV) or PtRuSA-CN (289.7 eV). This suggests that the coexistence of Pt-Ru and rich $\mathrm{N}$ vacancies synergistically improves the electron density of partial C atoms. This synergistic effect also appears in the $\mathrm{N}$ 1s spectrum. A remarkably lower peak at $399.8 \mathrm{eV}$ appears in PtRuSA-CN620 compared to those in RuSA-CN620 (400.6 eV), PtSA-CN620 (400.6 eV) or PtRuSA-CN (400.2 eV), associated with $\mathrm{N}_{2 \mathrm{C}}$ (Fig. 2h). ${ }^{22,24}$ Besides, the peak at $398.5 \mathrm{eV}$ in PtRuSA-CN620, corresponding to $\mathrm{N}_{3 \mathrm{C}}$, also shows a slight red shift compared to those in other samples. In the Ru $3 p$ spectrum, no obvious difference occurs in all samples (Fig. 2i). However, the Pt $4 \mathrm{f}$ spectrum exhibits some diversity in PtSA-CN620, PtRuSACN620 and PtRuSA-CN (Fig. 2j). Especially, a relatively high peak at $78.8 \mathrm{eV}$ is only observed in PtSA-CN620, corresponding to the oxidized Pt species. However, the addition of Ru removes this peak in PtRuSA-CN620 and PtRuSA-CN, implying the promotion effect of Ru on the reduction of Pt. Besides, the peak at $72.8 \mathrm{eV}$ in PtRuSA-CN620 is lower than that $(73.0 \mathrm{eV})$ in PtRuSA-CN, further confirming the lower chemical valence of Pt in PtRuSA-CN620, which is consistent with the above XANES. Combining the results of $\mathrm{C}$ and $\mathrm{N}$ 1s spectra, it is speculated that the Pt-Ru monomers on the $\mathrm{N}_{2 \mathrm{C}}$ and $\mathrm{C}_{2 \mathrm{C}}$ sites of PtRuSACN620 build an electron-rich region.

To illustrate the origination of the relationship between the coordination structure and electronic properties of neighboring $\mathrm{Pt}-\mathrm{Ru}$ monomers at the atomic level, density functional theory (DFT)-based theoretical simulation was conducted (Fig. 3). As a comparison, the neighboring $\mathrm{Ru}-\mathrm{Ru} / \mathrm{Pt}-\mathrm{Pt}$ and isolated $\mathrm{Ru} / \mathrm{Pt}$ monomers are also considered. Based on the coordination environment of $\mathrm{Pt}$ and $\mathrm{Ru}$, nine models are simulated, denoted as $\mathrm{C}-\mathrm{Ru}-\mathrm{Ru}-\mathrm{N}, \mathrm{C}-\mathrm{Pt}-\mathrm{Pt}-\mathrm{N}, \mathrm{C}-\mathrm{Pt}-\mathrm{Ru}-\mathrm{N}, \mathrm{C}-\mathrm{Ru}-\mathrm{Pt}-\mathrm{N}, \mathrm{N}-\mathrm{Pt}-\mathrm{Ru}-$ $\mathrm{N}, \quad \mathrm{N}-\mathrm{Ru}-\mathrm{N}, \mathrm{C}-\mathrm{Ru}-\mathrm{N}, \quad \mathrm{N}-\mathrm{Pt}-\mathrm{N}$ and $\mathrm{C}-\mathrm{Pt}-\mathrm{N}$, respectively 


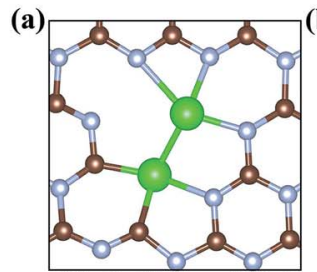

(d)

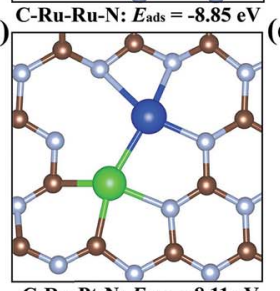

(g)

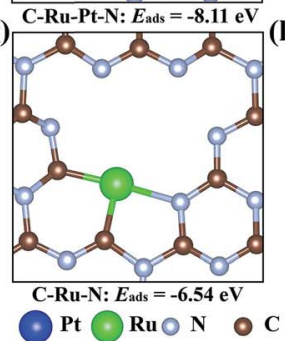

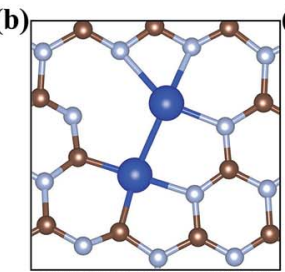

C-Pt-Pt-N: $E_{\text {ads }}=-7.68 \mathrm{eV}$
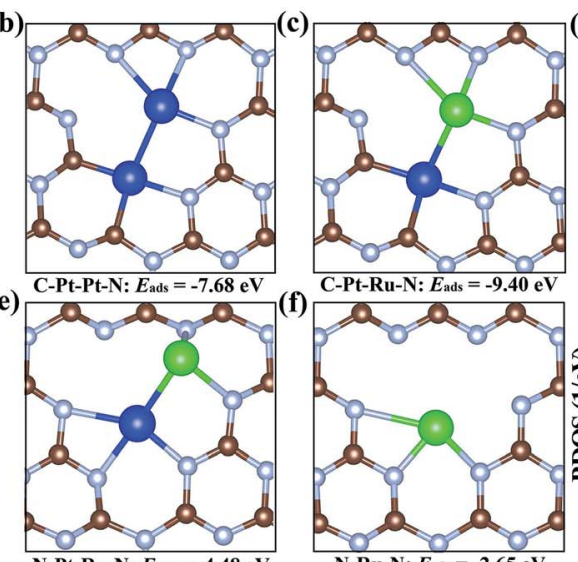

(f) $\mathrm{C}-\mathrm{Pt}-1$
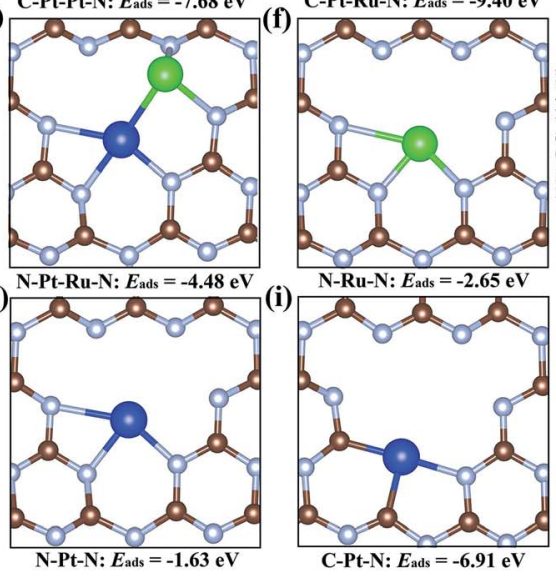

.

Pt-Ru-N: $E_{\text {ads }}=-9.40 \mathrm{eV}$

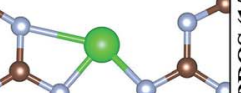

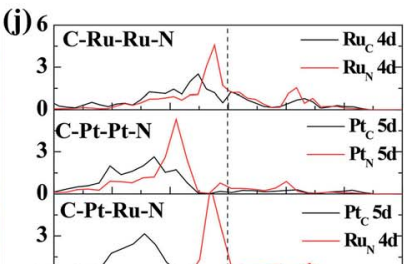
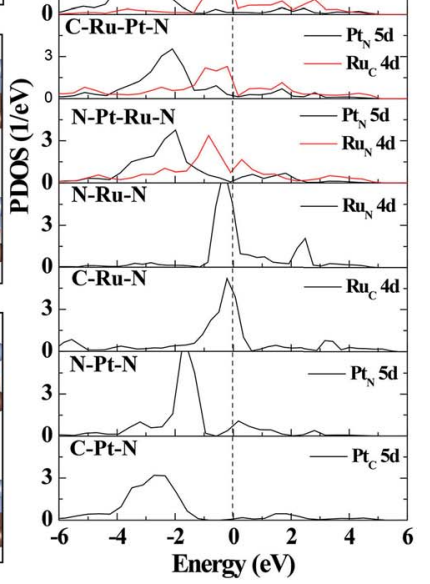

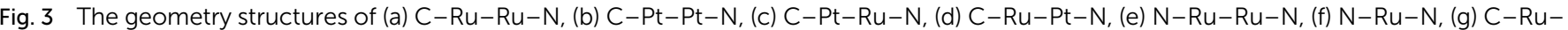

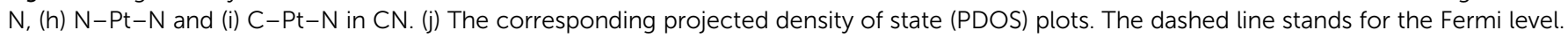

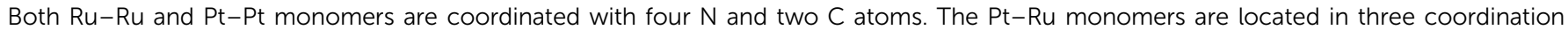

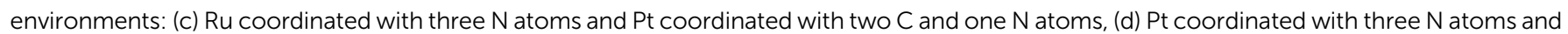
$\mathrm{Ru}$ coordinated with two $\mathrm{C}$ and one $\mathrm{N}$ atoms and (e) Ru coordinated with three $\mathrm{N}$ atoms and Pt coordinated with three $\mathrm{N}$ atoms.

(Fig. 3a-i). The calculated results confirm that the $\mathrm{Pt}-\mathrm{Ru}$ monomers with the coordination structure of $\mathrm{C}-\mathrm{Pt}-\mathrm{Ru}-\mathrm{N}$ is more stable than the $\mathrm{Ru}-\mathrm{Ru} / \mathrm{Pt}-\mathrm{Pt}$ monomers, isolated $\mathrm{Ru} / \mathrm{Pt}$ atoms or other Pt-Ru monomers, which is attributed to their more negative adsorption energy $\left(E_{\text {ads }}\right)$ by forming two Pt-C, one $\mathrm{Pt}-\mathrm{N}$ and three $\mathrm{Ru}-\mathrm{N}$ bonds. Moreover, the formation energy of the C-Pt-Ru-N structure is remarkably $4.9 \mathrm{eV}$ more negative than that of $\mathrm{N}-\mathrm{Pt}-\mathrm{Ru}-\mathrm{N}$ (Fig. 3e), suggesting the important role of $\mathrm{N}$ vacancies in stabilizing the Pt-Ru monomers. Furthermore, the corresponding projected density of states (PDOS) of the above structures was calculated to investigate their electronic properties. The results show that the $5 \mathrm{~d}$ states of $\mathrm{Pt}$ in $\mathrm{C}-\mathrm{Pt}-\mathrm{Ru}-\mathrm{N}$ are located in the most negative region compared to those in the other structures (Fig. 3j). This means that the PtSA in C-Pt-Ru-N is an electron-rich center. However, the $4 \mathrm{~d}$ states of Ru show relatively less shift with the change in its coordination structure. This finding well explains the results of XAFS and XPS. This electron-rich effect in the C$\mathrm{Pt}-\mathrm{Ru}-\mathrm{N}$ structure is probably beneficial to some reductiondependent catalytic reactions, such as the catalytic CO oxidation with $\mathrm{O}_{2}$ as the oxidizing agent.

The catalytic $\mathrm{CO}$ oxidation, performed in a continuous flow fixed bed quartz microreactor, was used to reveal the synergistic effect between neighboring Pt-Ru monomers. ${ }^{30}$ The results show that PtRuSA-CN620 possesses a lowest conversion temperature $\left(T_{100 \%}\right)$ of $150{ }^{\circ} \mathrm{C}$ compared to RuSA-CN620, PtSACN620, PtRuSA-CN and PtRuNP-CN620 (Fig. 4a). This suggests the synergistic promotion effect of $\mathrm{Pt}-\mathrm{Ru}$ monomers and $\mathrm{N}$ vacancies on the catalytic $\mathrm{CO}$ oxidation, which is attributed to the active $\mathrm{C}-\mathrm{Pt}-\mathrm{Ru}-\mathrm{N}$ structure. A stability test with PtRuSACN620 was carried out by a continuous reaction at $150{ }^{\circ} \mathrm{C}$ for 3000 min (Fig. S8 $\dagger$ ), which shows the good stability of PtRuSACN620. The XAFS characterization of PtRuSA-CN620 after the reaction indicates the atomic dispersion of $\mathrm{Pt}$ and $\mathrm{Ru}$ (Fig. S9†). Besides, the peaks between 2 and $3 \AA$ in Fig. S9a and b† show the existence of Pt-Ru monomers, confirming its high stability. The corresponding HRTEM image confirms that no obvious particles appear in PtRuSA-CN620 after the reaction (Fig. S10†), which also implies the stability of PtRuSA-CN620.

In situ DRIFTS measurement was further performed to determine the catalytic reaction mechanism on different samples (Fig. 4b). The results reveal that the $\mathrm{CO}$ adsorption only shows two weak stretching vibration peaks at 2171 and $2111 \mathrm{~cm}^{-1}$ on PtRuSA-CN620 in the catalytic reaction, corresponding to the physical and chemical adsorption of CO, respectively. ${ }^{5,29}$ In comparison, two similar peaks also appear in pure CN620 and PtSA-CN620 (Fig. S11†). Though the ratio of chemical CO adsorption of PtSA-CN620 to physical CO adsorption is slightly higher than that of pure CN620, the improved chemical CO adsorption on PtSA-CN620 is far weaker than those in the previous literature. ${ }^{5,31,32}$ Hence, the shown CO adsorption on PtSA produces little effect on the catalytic reaction since most PtSAs are free of CO adsorption. This suggests that the $\mathrm{CO}$ adsorption is independent of $\mathrm{Pt}$ or $\mathrm{Ru}$ in the catalytic reaction. Furthermore, the stability of $\mathrm{CO}$ adsorption on PtRuSA-CN620 was examined, revealing that $\mathrm{CO}$ adsorption on 
(a)

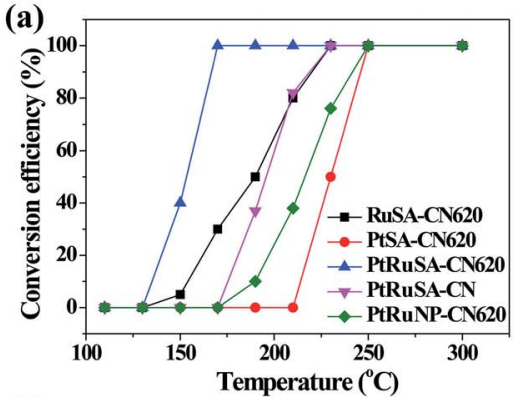

(c)

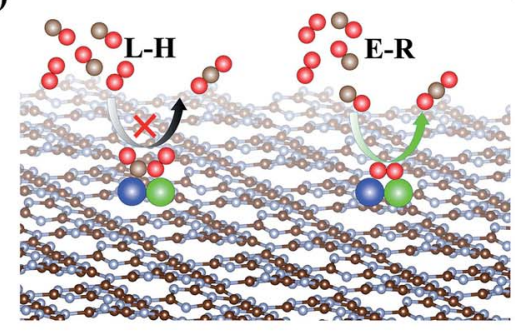

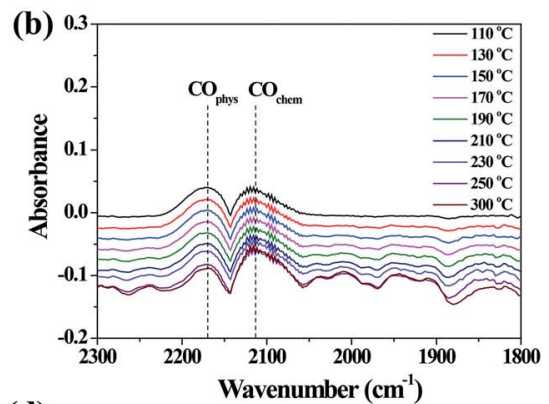

(d)

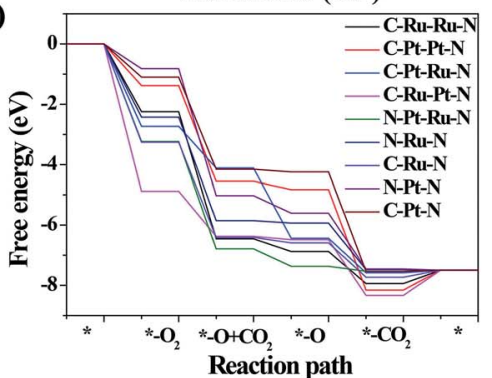

(e)

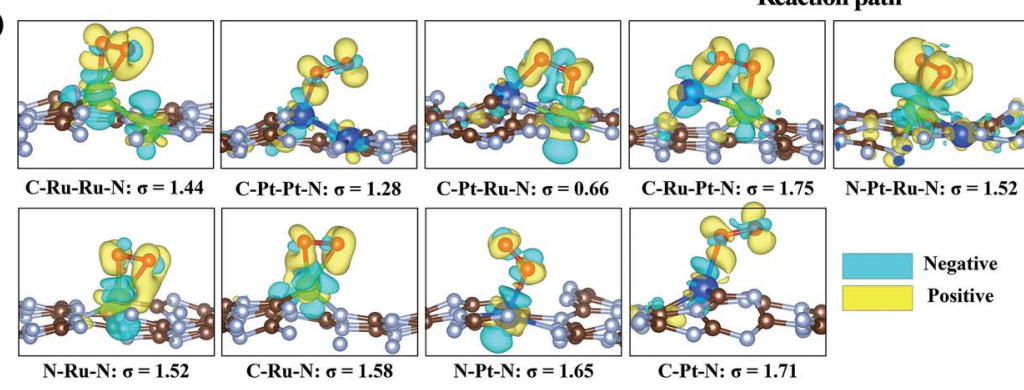

Fig. 4 (a) CO conversion as a function of temperature over the as-prepared samples at CO concentration $=1$ vol\%. (b) The in situ infrared spectra of CO oxidation on PtRuSA-CN620. (c) Reaction mechanisms of CO oxidation. (d) The free energy pathways of catalytic CO oxidation on the CRu-Ru-N, C-Pt-Pt-N, C-Pt-Ru-N, C-Ru-Pt-N, N-Pt-Ru-N, N-Ru-N, C-Ru-N, N-Pt-N and C-Pt-N structures. (e) The geometry structures and charge density difference mappings of $\mathrm{O}_{2}$ adsorptions. The overall geometry structures of $\mathrm{CO}$ oxidation pathways are shown in Fig. S13. $\dagger$ The sky blue and yellow isosurfaces stand for the negative and positive charges, respectively. The isosurface of charge density is set to 0.005 e $\AA^{-3}$ in all figures.

PtRuSA-CN620 is weak (Fig. S12†). Hence, CO adsorption in its catalytic oxidation is not dominant. In general, the catalytic $\mathrm{CO}$ oxidation follows two mechanisms: Langmuir-Hinshelwood (L-H) and Eley-Rideal (E-R) mechanisms (Fig. 4c). ${ }^{31}$ In the L-H mechanism, both $\mathrm{CO}$ and $\mathrm{O}_{2}$ are adsorbed on the catalyst surface, such as Pt-loaded $\mathrm{TiO}_{2}$. The corresponding IR observation should obtain an obvious $\mathrm{CO}$ adsorption peak. However, the above IR observation does not support this mechanism. For the E-R mechanism, only $\mathrm{CO}$ or $\mathrm{O}_{2}$ is adsorbed on the catalyst surface. Hence, the catalytic $\mathrm{CO}$ oxidation on the as-prepared samples can be attributed to the $\mathrm{E}-\mathrm{R}$ mechanism where the $\mathrm{CO}$ adsorption is not necessary. Besides, it is speculated that the $\mathrm{O}_{2}$ activation plays an important role in the catalytic $\mathrm{CO}$ oxidation.

To explain the high activity of PtRuSA-CN620, DFT simulation on the catalytic $\mathrm{CO}$ oxidation process was performed. Considering the structural features of the as-prepared samples, the simulations were based on the above $\mathrm{C}-\mathrm{Ru}-\mathrm{Ru}-\mathrm{N}, \mathrm{C}-\mathrm{Pt}-\mathrm{Pt}-$ $\mathrm{N}, \mathrm{C}-\mathrm{Pt}-\mathrm{Ru}-\mathrm{N}, \mathrm{C}-\mathrm{Ru}-\mathrm{Pt}-\mathrm{N}, \mathrm{N}-\mathrm{Pt}-\mathrm{Ru}-\mathrm{N}, \mathrm{N}-\mathrm{Ru}-\mathrm{N}, \mathrm{C}-\mathrm{Ru}-\mathrm{N}$, $\mathrm{N}-\mathrm{Pt}-\mathrm{N}$ and $\mathrm{C}-\mathrm{Pt}-\mathrm{N}$ structures (Fig. S13†). The results show that all reaction steps except the final $\mathrm{CO}_{2}$ desorption step are exothermic (Fig. 4d). For a catalytic reaction, an excessive energy decrease in one step is often not beneficial to the whole reaction with respect to thermodynamics, which easily causes a high reaction barrier or less negative reaction energy in the other steps. Thus balancing the energy decrease in the reaction steps is significant for the catalytic reaction. Here we use a standard deviation $(\sigma)$ method to evaluate the catalytic CO oxidation activity of the above structures (details in the Theoretical simulation of the ESI $\dagger$ ). In this method, the smaller standard deviation among the reaction energies of different steps endows the corresponding structure with higher catalytic activity. The fore four exothermic steps, including $\mathrm{O}_{2}$ adsorption, CO oxidation by the adsorbed $\mathrm{O}_{2}$ and $\mathrm{O}$ species and the first $\mathrm{CO}_{2}$ desorption are considered. The standard deviations of reaction step energies in C-Ru-Ru-N, C-Pt-Pt-N, C-Pt-Ru-N, C-Ru-Pt$\mathrm{N}, \mathrm{N}-\mathrm{Pt}-\mathrm{Ru}-\mathrm{N}, \mathrm{N}-\mathrm{Ru}-\mathrm{N}, \mathrm{C}-\mathrm{Ru}-\mathrm{N}, \mathrm{N}-\mathrm{Pt}-\mathrm{N}$ and $\mathrm{C}-\mathrm{Pt}-\mathrm{N}$ are calculated to be $1.44,1.28,0.66,1.75,1.52,1.52,1.58,1.65$, and $1.71 \mathrm{eV}$, respectively (Fig. 4e). These results suggest that the C$\mathrm{Pt}-\mathrm{Ru}-\mathrm{N}$ structure possesses optimized catalytic reaction steps for $\mathrm{CO}$ oxidation. This is originated from the effective activation of $\mathrm{O}_{2}$ between $\mathrm{Pt}-\mathrm{Ru}$ monomers by causing bridge-type $\mathrm{O}_{2}$ 
adsorption with one $\mathrm{Pt}-\mathrm{O}$ bond and one $\mathrm{Ru}-\mathrm{O}$ bond (Fig. 4e). In this $\mathrm{O}_{2}$ adsorption, the electrons (sky blue region) can be effectively aggregated between two $\mathrm{O}$ atoms, which contributes to the activation of $\mathrm{O}_{2}$. However, on $\mathrm{C}-\mathrm{Ru}-\mathrm{Ru}-\mathrm{N}$ and $\mathrm{C}-\mathrm{Pt}-\mathrm{Pt}-\mathrm{N}$ structures, the $\mathrm{O}_{2}$ activation only occurs on one RuSA or PtSA, corresponding to a less negative reaction energy. Though one $\mathrm{Pt}-\mathrm{O}$ bond and one $\mathrm{Ru}-\mathrm{O}$ bond can simultaneously form in the $\mathrm{O}_{2}$ activation on the $\mathrm{C}-\mathrm{Ru}-\mathrm{Pt}-\mathrm{N}$ structure, the reaction energy is excessively negative, leading to the low oxidizing activity of the formed $\mathrm{O}$ species. On the $\mathrm{N}-\mathrm{Pt}-\mathrm{Ru}-\mathrm{N}$ structure, the reaction energy of the first $\mathrm{CO}$ oxidation step is also excessively negative. Besides, the left $\mathrm{O}$ species on the RuSA is less active, which leads to a less negative reaction energy in the second $\mathrm{CO}$ oxidation step. As for the isolated $\mathrm{Ru}$ or $\mathrm{Pt}$ atoms, the bridge-type $\mathrm{O}_{2}$ adsorption is not observed. Hence, the DFT results confirm that the best site for the catalytic CO oxidation is the $\mathrm{C}-\mathrm{Pt}-\mathrm{Ru}-\mathrm{N}$ structure. According to the above experimental analysis, PtRuSA-CN620 possesses more C-Pt-Ru-N structures. Thus the theoretical simulations well explain the highest catalytic $\mathrm{CO}$ oxidation activity of PtRuSA-CN620 compared to the other samples.

\section{Conclusions}

To summarize, we constructed neighboring Pt-Ru monomers on a $\mathrm{N}$-vacancy-rich $\mathrm{g}-\mathrm{C}_{3} \mathrm{~N}_{4}$ surface by an icing-assisted photocatalytic reduction method. Aberration-corrected-STEM and XAFS confirms the existence of neighboring Pt-Ru monomers in the $\mathrm{N}_{2 \mathrm{C}}$ and $\mathrm{C}_{2 \mathrm{C}}$ sites of N-vacancy-rich g- $\mathrm{C}_{3} \mathrm{~N}_{4}$. Using DFT simulations, an electron-rich $\mathrm{C}-\mathrm{Pt}-\mathrm{Ru}-\mathrm{N}$ structure was defined as not only a stable thermodynamic model of neighboring Pt$\mathrm{Ru}$ monomers, but also an optimized site for the catalytic CO oxidation compared to neighboring $\mathrm{Ru}-\mathrm{Ru} / \mathrm{Pt}-\mathrm{Pt}$ monomers or isolated $\mathrm{Ru} / \mathrm{Pt}$ atoms. This finding demonstrates an opportunity for developing a new class of atomically dispersed metal catalysts.

\section{Conflicts of interest}

There are no conflicts to declare.

\section{Acknowledgements}

The authors are grateful for the financial support of this work from the Beijing Natural Science Foundation (JQ18005), the National Basic Research Program of China (Grant No. 2016YFB0100201), and the National Natural Science Foundation of China (Grant No. 51671003), and start-up support from Peking University and the Young Thousand Talented Program. The authors would like to thank BSRF, NSRL and SSRF for the synchrotron beam time. The theoretical calculations and in situ IR measurements were performed by Jincai Zhao's group of the Institute of Chemistry, Chinese Academy of Sciences.

\section{Notes and references}

1 Y. J. Cao, S. Chen, Q. Q. Luo, H. Yan, Y. Lin, W. Liu, L. L. Cao, J. L. Lu, J. L. Yang, T. Yao and S. Q. Wei, Angew. Chem., Int. Ed., 2017, 56, 12191-12196.

2 W. Liu, L. L. Cao, W. R. Cheng, Y. J. Cao, X. K. Liu, W. Zhang, X. L. Mou, L. L. Jin, X. S. Zheng, W. Che, Q. H. Liu, T. Yao and S. Q. Wei, Angew. Chem., Int. Ed., 2017, 56, 9312-9317.

3 J. Lin, A. Q. Wang, B. T. Qiao, X. Y. Liu, X. F. Yang, X. D. Wang, J. X. Liang, J. X. Li, J. Y. Liu and T. Zhang, J. Am. Chem. Soc., 2013, 135, 15314-15317.

4 J. Zhang, X. Wu, W. C. Cheong, W. X. Chen, R. Lin, J. Li, L. R. Zheng, W. S. Yan, L. Gu, C. Chen, Q. Peng, D. S. Wang and Y. D. Li, Nat. Commun., 2018, 9, 1002.

5 K. Ding, A. Gulec, A. M. Johnson, N. M. Schweitzer, G. D. Stucky, L. D. Marks and P. C. Stair, Science, 2015, 350, 189-192.

6 S. W. Cao, H. Li, T. Tong, H. C. Chen, A. C. Yu, J. G. Yu and H. M. Chen, Adv. Funct. Mater., 2018, 28, 1802169.

7 H. J. Shen, E. Gracia-Espino, J. Y. Ma, K. T. Zang, J. Luo, L. Wang, S. S. Gao, X. Mamat, G. Z. Hu, T. Wagberg and S. J. Guo, Angew. Chem., Int. Ed., 2017, 56, 13800-13804.

8 Z. P. Zhang, J. T. Sun, F. Wang and L. M. Dai, Angew. Chem., Int. Ed., 2018, 57, 9038-9043.

9 W. G. Liu, L. L. Zhang, X. Liu, X. Y. Liu, X. F. Yang, S. Miao, W. T. Wang, A. Q. Wang and T. Zhang, J. Am. Chem. Soc., 2017, 139, 10790-10798.

10 X. Wang, W. X. Chen, L. Zhang, T. Yao, W. Liu, Y. Lin, H. X. Ju, J. C. Dong, L. R. Zheng, W. S. Yan, X. S. Zheng, Z. J. Li, X. Q. Wang, J. Yang, D. S. He, Y. Wang, Z. X. Deng, Y. E. Wu and Y. D. Li, J. Am. Chem. Soc., 2017, 139, 94199422.

11 Y. Y. Zhao, K. R. Yang, Z. C. Wang, X. X. Yan, S. F. Cao, Y. F. Ye, Q. Dong, X. Z. Zhang, J. E. Thorne, L. Jin, K. L. Materna, A. Trimpalis, H. Y. Bai, S. C. Fakra, X. Y. Zhong, P. Wang, X. Q. Pan, J. H. Guo, M. Flytzani-Stephanopoulos, G. W. Brudvig, V. S. Batista and D. W. Wang, Proc. Natl. Acad. Sci. U. S. A., 2018, 115, 2902-2907.

12 M. Yang, S. Li, Y. Wang, J. A. Herron, Y. Xu, L. F. Allard, S. Lee, J. Huang, M. Mavrikakis and M. FlytzaniStephanopoulos, Science, 2014, 346, 1498-1501.

13 G. X. Pei, X. Y. Liu, A. Q. Wang, A. F. Lee, M. A. Isaacs, L. Li, X. L. Pan, X. F. Yang, X. D. Wang, Z. J. Tai, K. Wilson and T. Zhang, ACS Catal., 2015, 5, 3717-3725.

14 S. Yang, J. Kim, Y. J. Tak, A. Soon and H. Lee, Angew. Chem., Int. Ed., 2016, 55, 2058-2062.

15 Y. Kwon, T. Y. Kim, G. Kwon, J. Yi and H. Lee, J. Am. Chem. Soc., 2017, 139, 17694-17699.

16 H. Yan, H. Cheng, H. Yi, Y. Lin, T. Yao, C. L. Wang, J. J. Li, S. Q. Wei and J. L. Lu, J. Am. Chem. Soc., 2015, 137, 1048410487.

17 G. Kyriakou, M. B. Boucher, A. D. Jewell, E. A. Lewis, T. J. Lawton, A. E. Baber, H. L. Tierney, M. FlytzaniStephanopoulos and E. C. H. Sykes, Science, 2012, 335, 1209-1212. 
18 H. L. Li, L. B. Wang, Y. Z. Dai, Z. T. Pu, Z. H. Lao, Y. W. Chen, M. L. Wang, X. S. Zheng, J. F. Zhu, W. H. Zhang, R. Si, C. Ma and J. Zeng, Nat. Nanotechnol., 2018, 13, 411-417.

19 S. B. Tian, Q. Fu, W. X. Chen, Q. C. Feng, Z. Chen, J. Zhang, W. C. Cheong, R. Yu, L. Gu, J. C. Dong, J. Luo, C. Chen, Q. Peng, C. Draxl, D. S. Wang and Y. D. Li, Nat. Commun., 2018, 9, 2353.

20 M. Yang, J. L. Liu, S. Lee, B. Zugic, J. Huang, L. F. Allard and M. Flytzani-Stephanopoulos, J. Am. Chem. Soc., 2015, 137, 3470-3473.

21 J. W. Wan, W. X. Chen, C. Y. Jia, L. R. Zheng, J. C. Dong, X. S. Zheng, Y. Wang, W. S. Yan, C. Chen, Q. Peng, D. S. Wang and Y. D. Li, Adv. Mater., 2018, 30, 1705369.

22 Y. Y. Kang, Y. Q. Yang, L. C. Yin, X. D. Kang, G. Liu and H. M. Cheng, Adv. Mater., 2015, 27, 4572-4577.

23 Z. Peng, L. Jianping, T. Yonghua, C. Yuguang, L. Fei and G. Shaojun, Appl. Catal., B, 2018, 238, 161-167.

24 Y. Y. Kang, Y. Q. Yang, L. C. Yin, X. D. Kang, L. Z. Wang, G. Liu and H. M. Cheng, Adv. Mater., 2016, 28, 6471-6477.

25 W. G. Tu, Y. Xu, J. J. Wang, B. W. Zhang, T. H. Zhou, S. M. Yin, S. Y. Wu, C. M. Li, Y. Z. Huang, Y. Zhou, Z. G. Zou, J. Robertson, M. Kraft and R. Xu, ACS Sustainable Chem. Eng., 2017, 5, 7260-7268.
26 P. Zhou, F. Lv, N. Li, Y. Zhang, Z. Mu, Y. Tang, J. Lai, Y. Chao, M. Luo, F. Lin, J. Zhou, D. Su and S. Guo, Nano Energy, 2018, 56, 127-137.

27 H. H. Wei, K. Huang, L. Zhang, B. H. Ge, D. Wang, J. L. Lang, J. Y. Ma, D. Wang, S. Zhang, Q. Y. Li, R. Y. Zhang, N. Hussain, M. Lei, L. M. Liu and H. Wu, Angew. Chem., Int. Ed., 2018, 57, 3354-3359.

28 H. H. Wei, K. Huang, D. Wang, R. Y. Zhang, B. H. Ge, J. Y. Ma, B. Wen, S. Zhang, Q. Y. Li, M. Lei, C. Zhang, J. Irawan, L. M. Liu and H. Wu, Nat. Commun., 2017, 8, 1490.

29 Z. L. Zhang, Y. H. Zhu, H. Asakura, B. Zhang, J. G. Zhang, M. X. Zhou, Y. Han, T. Tanaka, A. Q. Wang, T. Zhang and N. Yan, Nat. Commun., 2017, 8, 16100.

30 B. Z. Gao, J. G. Deng, Y. X. Liu, Z. X. Zhao, X. W. Li, Y. Wang and H. X. Dai, Chin. J. Catal., 2013, 34, 2223-2229.

31 H. Zhang, C. Wang, H. L. Sun, G. Fu, S. Chen, Y. J. Zhang, B. H. Chen, J. R. Anema, Z. L. Yang, J. F. Li and Z. Q. Tian, Nat. Commun., 2017, 8, 15447.

32 L. DeRita, S. Dai, K. Lopez-Zepeda, N. Pham, G. W. Graham, X. Q. Pan and P. Christopher, J. Am. Chem. Soc., 2017, 139, 14150-14165. 